\title{
Measurement of Proton-driven Antiport in Escherichia coli
}

Scarlett R. Holdsworth and Christopher J. Law

Institute for Global Food Security, Queen's University Belfast, Belfast, UK

*For correspondence: c.law@qub.ac.uk

[Abstract] Secondary active transport of substrates across the inner membrane is vital to the bacterial cell. Of the secondary active transporter families, the ubiquitous major facilitator superfamily (MFS) is the largest and most functionally diverse (Reddy et al., 2012). Recently, it was reported that the MFS multidrug efflux protein MdtM from Escherichia coli ( $E$. coli) functions physiologically in protection of bacterial cells against bile salts (Paul et al., 2014). The MdtM transporter imparts bile salt resistance to the bacterial cell by coupling the exchange of external protons $\left(\mathrm{H}^{+}\right)$to the efflux of bile salts from the cell interior via an antiport reaction. This protocol describes, using fluorometry, how to detect the bile salt $/ \mathrm{H}^{+}$antiport activity of MdtM in inverted membrane vesicles of an antiporter-deficient strain of $E$. coli TO114 cells by measuring transmembrane $\Delta \mathrm{pH}$. This method exploits the changes that occur in the intensity of the fluorescence signal (quenching and dequenching) of the $\mathrm{pH}$-sensitive dye acridine orange in response to changes in $\left[\mathrm{H}^{+}\right]$in the vesicular lumen. Due to low levels of endogenous transporter expression that would normally make the contribution of individual transporters such as MdtM to proton-driven antiport difficult to detect, the method typically necessitates that the transporter of interest be overexpressed from a multicopy plasmid. Although the first section of the protocol described here is very specific to the overexpression of MdtM from the pBAD/Myc-His A expression vector, the protocol describing the subsequent measurement of bile salt efflux by MdtM can be readily adapted for measurement of antiport of other substrates by any other antiporter that exchanges protons for countersubstrate.

\section{Materials and Reagents}

1. pBAD/Myc-His A expression vector (Life Technologies, catalog number: V440-01)

2. L-(+)-arabinose (Sigma-Aldrich, catalog number: A3256)

3. Carbenicillin (Carbenicillin Direct)

4. Agar (Sigma-Aldrich, catalog number: A1296)

5. Tryptone (Fluka, catalog number: T7293)

6. Yeast extract (Fluka, catalog number: 92114)

7. Potassium chloride (Thermo Fisher Scientific, catalog number: BP366)

8. Escherichia coli (E. coli) TO114 (gift of Prof. Hiroshi Kobayashi, Chiba University, Japan) 
9. Acridine orange hemi (zinc chloride) salt (Sigma-Aldrich, catalog number: A6014)

10. BisTris propane (BTP) (Sigma-Aldrich, catalog number: B6755)

11. Phenylmethanesulfonyl fluoride (PMSF) (Sigma-Aldrich, catalog number: P7626)

12. Deoxyribonuclease I (DNase) from bovine pancreas (Sigma-Aldrich, catalog number: DN25)

13. Carbonyl cyanide 3-chlorophenylhydrazone (CCCP) (Sigma-Aldrich, catalog number: C2759)

14. Sodium DL-lactate solution $50 \%$ aqueous (VWR International, catalog number: 27927.298)

15. Magnesium sulphate heptahydrate $\left(\mathrm{MgSO}_{4} \cdot 7 \mathrm{H}_{2} \mathrm{O}\right)$ (Thermo Fisher Scientific, catalog number: M/1000/60)

16. Sodium cholate hydrate (Sigma-Aldrich, catalog number: C1254)

17. Absolute ethanol (Thermo Fisher Scientific, catalog number: E/0650DF/17)

18. High purity (18 $\mathrm{M} \Omega)$ Millipore or AnalR water

19. Choline chloride (Sigma-Aldrich, catalog number: C1879)

20. Sucrose (Sigma-Aldrich, catalog number: 84097)

21. DL-dithiothreitol (Sigma-Aldrich, catalog number: 43815)

22. TRIZMA base (Sigma-Aldrich, catalog number: T1503)

23. 32\% hydrochloric acid (VWR International, catalog number: 20254.321)

24. LBK agar (see Recipes)

25. LBK liquid medium (see Recipes)

26. Tris/choline/dithiothreitol/sucrose (TCDS) buffer (see Recipes)

27. Transport assay buffer (see Recipes)

28. $200 \mathrm{mM}$ sodium DL-lactate solution (see Recipes)

\section{Equipment}

1. Temperature-controlled shaking incubator for bacterial growth

2. Petri dishes for bacterial colony growth

3. $100 \mathrm{ml}$ conical flasks

4. $250 \mathrm{ml}$ conical flasks (x2)

5. $5,000 \mathrm{ml}$ conical flasks $(\mathrm{x} 2)$

6. Large ice bucket

7. Refrigerated, large capacity centrifuge and rotor for harvesting bacterial cells

8. $1,000 \mathrm{ml}$ or $500 \mathrm{ml}$ centrifuge pots and lids

9. Benchtop vortexer

10. $100 \mathrm{ml}$ beaker and stir bar to fit 
11. Magnetic stirrer

12. $25 \mathrm{ml}$ disposable plastic pipettes

13. Selection of single channel pipettes $(1,000 \mu \mathrm{l}, 100 \mu \mathrm{l}, 20 \mu \mathrm{l}, 10 \mu \mathrm{l})$

14. Pipette tips for above

15. Refrigerated centrifuge and rotor capable of spinning $\sim 50 \mathrm{ml}$ tubes at $18 \mathrm{k} \times \mathrm{g}$

16. Refrigerated ultracentrifuge, rotor and polycarbonate ultracentrifuge tubes capable of handling $\sim 30-50 \mathrm{ml}$ volumes

17. French Press (Thermo Fisher Scientific, catalogue number: FA-078)

18. Standard pressure cell (40 kpsi; $35 \mathrm{ml}$ capacity) (Thermo Fisher Scientific, catalog number: FA-031)

19. $50 \mathrm{ml}$ syringes (for filtering solutions)

20. $0.22 \mu \mathrm{m}$ sterile filters to fit $50 \mathrm{ml}$ syringe

21. $1 \mathrm{~L}$ and $500 \mathrm{ml}$ Duran bottles with lids

22. $1.5 \mathrm{ml}$ Eppendorf tubes

23. Medical wipes (Kimwipes ${ }^{\circledR}$ )

24. Parafilm

25. UV/vis spectrophotometer and $10 \mathrm{~mm}$ pathlength quartz cuvette

26. $10 \times 4 \mathrm{~mm}, 1,400 \mu \mathrm{l}$ volume quartz cuvette for fluorescence spectroscopy (Hellma, catalog number: 104F-QG)

27. Small magnetic stir bar to fit inside quartz cuvette

28. Fluorometer e.g. Fluoromax-4 (Horiba) capable of performing time-based acquisition measurements and fitted with a temperature controlled cuvette holder and stirrer

29. Source of compressed air (either aerosol can or fixed supply) for drying cuvette

\section{Procedure}

A. Growth and harvesting of bacterial cultures and preparation of inverted membrane vesicles

1. Perform a fresh transformation with the pBAD/Myc-His A plasmid DNA encoding wild type or mutant transporter (or your vector of choice encoding your transporter of interest) into chemically competent E. coli TO114 cells. Plate the cells onto Luria Bertani Potassium (LBK) agar containing $100 \mu \mathrm{g} / \mathrm{ml}$ carbenicillin for selection. LBK agar must be used instead of regular Luria Bertani (LB) agar because the latter contains $\mathrm{NaCl}$ and the TO114 strain is sensitive to this salt due to deletion of the chromosomally encoded $\mathrm{Na}^{+} / \mathrm{H}^{+}$antiporter NhaA. Incubate the plate overnight $(\sim 15$ to $\sim 18 \mathrm{~h})$ at $37^{\circ} \mathrm{C}$.

2. Pick a few single colonies from the agar plate and use to inoculate $2 \times 250 \mathrm{ml}$ conical flasks, each containing $100 \mathrm{ml}$ of LBK liquid medium supplemented with $100 \mu \mathrm{g} / \mathrm{ml}$ carbenicillin. Grow the cultures overnight $(\sim 15 \mathrm{~h})$ at $30{ }^{\circ} \mathrm{C}$ with $250 \mathrm{rpm}$ shaking in a 
temperature-controlled shaking incubator. Measure the optical density at $600 \mathrm{~nm}\left(\mathrm{OD}_{600}\right)$ of the culture using a spectrophotometer; it should be between 3.0-3.3. If the $\mathrm{OD}_{600}$ is less than 3.0, then incubate for a further 0.5-1.0 $\mathrm{h}$ and re-measure. If the $\mathrm{OD}_{600}$ is greater than 3.3, the cultures have overgrown and fresh cultures will need to be prepared.

3. Inoculate $2 \times 5 \mathrm{~L}$ conical flasks, each containing $1,000 \mathrm{ml}$ of LBK liquid medium supplemented with $100 \mu \mathrm{g} / \mathrm{ml}$ carbenicillin, with $15 \mathrm{ml}$ of overnight culture. Incubate at 32 ${ }^{\circ} \mathrm{C}$ with $270 \mathrm{rpm}$ shaking for $\sim 2.5 \mathrm{~h}$ in a temperature-controlled shaking incubator. The $\mathrm{OD}_{600}$ should be $\sim 0.6$. Drop the temperature to $25^{\circ} \mathrm{C}$ and grow with $270 \mathrm{rpm}$ shaking until the $\mathrm{OD}_{600}$ is 1.0 . This usually takes between 0.5 to $1.0 \mathrm{~h}$.

4. Induce overexpression of MdtM by addition of $0.1 \% \mathrm{w} / \mathrm{v} \mathrm{L}-(+)$-arabinose $[5 \mathrm{ml}$ of $20 \% \mathrm{w} / \mathrm{v}$ L-(+)-arabinose] to each flask. After addition of arabinose, grow the cells for a further 1.5 h at $25^{\circ} \mathrm{C}$ with $270 \mathrm{rpm}$ shaking prior to harvesting.

5. Transfer the E. coli TO114 cells that contain overexpressed transporter into $500 \mathrm{ml}$ or $1,000 \mathrm{ml}$ capacity centrifuge pots that have been pre-chilled on ice for at least $15 \mathrm{~min}$. Pre-cool the centrifuge to $4^{\circ} \mathrm{C}$ and harvest cells by centrifugation at $5,000 \times g$ for $20 \mathrm{~min}$.

6. Decant the supernatant and wash the pelleted cells by resuspending in chilled $\left(4{ }^{\circ} \mathrm{C}\right)$ TCDS buffer. Use $30 \mathrm{ml}$ of TCDS buffer for each one litre of cell culture that was pelleted. Maintain the cells on ice during this procedure. Harvest the washed cells by centrifugation as described in step A1 (above) and repeat the washing procedure. Resuspend the resultant cell pellet in $30 \mathrm{ml}$ of chilled TCDS buffer containing $2 \mathrm{mM}$ PMSF (which should be made up as a $100 \mathrm{mM}$ stock in ethanol and stored at $-20{ }^{\circ} \mathrm{C}$; ensure the solution is thawed thoroughly and vortexed vigorously before use) and $5 \mu \mathrm{M}$ DNase and maintain the mixture on ice.

Notes:

a. Typically, a 1 L culture of bacterial cells will provide sufficient material for these experiments.

b. Cells should be resuspended either by gentle vortexing using a benchtop vortexer or by gentle aspiration using a $25 \mathrm{ml}$ sterile plastic pipette.

7. Decant the resuspended cells into a $100 \mathrm{ml}$ beaker containing a stir bar, place on magnetic stirrer and stir in a cold room at $4{ }^{\circ} \mathrm{C}$ for $20 \mathrm{~min}$. Alternatively, place the beaker on ice in an ice bucket, place on the magnetic stirrer and stir for $20 \mathrm{~min}$.

8. The method for production of inverted vesicles relies on a combination of the fluid shear forces and decompression created as the cell mixture passes through the needle valve of a French pressure cell. Generate inverted membrane vesicles by a single passage of the resuspended cell mixture through a French pressure cell at a minimum of 4,000 psi. If the pressure is too low, inverted vesicles will not be formed. The pressure cell should be 
chilled on ice for $\sim 30$ min prior to use. The resulting inverted vesicle mixture should be collected in a $100 \mathrm{ml}$ conical flask kept on ice.

9. Decant the mixture into a pre-chilled $\sim 50 \mathrm{ml}$ centrifuge tube and remove any unbroken cells and cell debris by centrifugation at $18,000 \times g$ for 10 min at $4{ }^{\circ} \mathrm{C}$. Carefully decant the supernatant (do not disturb the pellet that contains unbroken cells and cell debris) containing the cell membrane vesicles into a pre-chilled 30-50 ml volume polycarbonate ultracentrifuge tube on ice.

10. Harvest the inverted vesicles by ultracentrifugation at $100,000 \times g$ for $1 \mathrm{~h}$ at $4{ }^{\circ} \mathrm{C}$. Carefully decant the supernatant and retain the pellet. Place the ultracentrifuge tube containing the pelleted vesicles on ice.

11. Resuspend the inverted vesicle pellet in $1 \mathrm{ml}$ of ice-cold TCDS buffer by gentle aspiration using a 1,000 $\mu \mathrm{l}$ pipette. Transfer the resuspended vesicles to a pre-chilled $1.5 \mathrm{ml}$ Eppendorf tube on ice for use in the transport assay. In our experience, vesicles stored on ice are stable for several hours.

12. Quantify the total membrane protein content of the inverted vesicles by UV absorbance spectroscopy at $280 \mathrm{~nm}$. Blank the spectrophotometer using a $10 \mathrm{~mm}$ pathlength quartz cuvette containing 1,000 $\mu \mathrm{l}$ of TCDS buffer. The buffer should be at room temperature to prevent frosting of the cuvette faces. Clean the faces of the cuvette using a fresh paper wipe prior to measurement. Once the spectrophotometer is blanked, remove $5 \mu \mathrm{l}$ of buffer from the cuvette using a $10 \mu \mathrm{l}$ pipette and replace with $5 \mu \mathrm{l}$ of vesicles. Cover the opening of the cuvette with a square of Parafilm and invert the cuvette a few times to ensure a homogeneous distribution of vesicles. Record the absorbance of the vesicle mixture at $280 \mathrm{~nm}$ and calculate the total membrane protein concentration assuming that an $A_{280}$ of 1.0 is equivalent to a protein concentration of $1.0 \mathrm{mg} / \mathrm{ml}$.

Notes:

a. Remember to multiply the $280 \mathrm{~nm}$ absorbance value you obtain by a factor of 200 to calculate the concentration of the undiluted vesicle mixture in $\mathrm{mg} / \mathrm{ml}$.

b. At this stage of the preparation, the resuspended vesicles can be transferred to tubes in aliquots of 25-100 $\mu \mathrm{l}$, snap-frozen in liquid nitrogen and stored at $-80{ }^{\circ} \mathrm{C}$ for subsequent use. Vesicles frozen in this way will retain their integrity for several months. However, if frozen vesicle stocks are used for the subsequent transport measurements, the vesicles must be thawed very slowly on ice prior to use to prevent their fracture.

B. Fluorometric antiport assays

1. In this section we describe the set-up parameters for a Fluoromax-4 fluorometer. These parameters, however, can form the basis for the set-up of other fluorometers. Once the 
instrument is switched on and the software booted up, set the temperature of the cuvette holder to $25^{\circ} \mathrm{C}$. Open the instrument software and select for time-based data acquisition with excitation and emission wavelengths of $492 \mathrm{~nm}$ and $525 \mathrm{~nm}$, respectively. Set the excitation and emission slit widths to $1.5 \mathrm{~nm}$ and $2.5 \mathrm{~nm}$, respectively.

2. Add an aliquot of inverted vesicles (which should be maintained on ice in TCDS buffer) to room temperature transport assay buffer containing the acridine orange probe in a 10 $\mathrm{mm} \times 4 \mathrm{~mm}$ quartz cuvette to a final concentration of $0.5 \mathrm{mg} / \mathrm{ml}$ membrane protein in a total volume of $1,500 \mu \mathrm{l}$. The longest pathlength of the cuvette should face the excitation light source. Place a small magnetic flea into the cuvette and stir the contents gently. Allow the vesicles and assay buffer to equilibrate for $\sim 200 \mathrm{sec}$.

3. Start recording the fluorescence emission. After approximately $50 \mathrm{sec}$, add $15 \mu \mathrm{l}$ of 200 $\mathrm{mM}$ stock sodium DL-lactate solution to the cuvette contents to give a final sodium DLlactate concentration of $\sim 2.0 \mathrm{mM}$. Addition of lactate energises the vesicles and generates a respiration dependent $\Delta \mathrm{pH}$ (acid inside) across the inverted vesicle membrane as $\mathrm{H}^{+}$is pumped into the vesicle interior. This causes a dequench of the acridine orange fluorescence signal (see Figure 1in Representative data).

4. Following the establishment of a $\Delta \mathrm{pH}$, monitor the acridine orange fluorescence dequench for a further $-200 \mathrm{sec}$ until it stabilises. Initiate MdtM-mediated, proton-driven antiport by adding substrate (in this case the bile salt sodium cholate) to the inverted vesicle mixture. We added $12.5 \mu \mathrm{l}$ of $250 \mathrm{mM}$ stock solution made up in high purity water to give a final concentration of sodium cholate in the cuvette of $\sim 2.0 \mathrm{mM}$. For other substrates we suggest testing a range varying from $1 \mathrm{mM}$ to $100 \mathrm{mM}$ to establish the concentration that gives the best dequench signal. Upon addition of substrate, there should be an immediate dequench (rise) of the acridine orange fluorescence emission signal (see Figure 1a) due to dissipation of the established $\Delta \mathrm{pH}$ as a result of MdtMmediated sodium cholate $/ \mathrm{H}^{+}$antiport activity and concomitant alkalinisation of the vesicle lumen.

5. Record the fluorescence dequench signal for $50 \mathrm{sec}$ to allow the antiport reaction to achieve a steady state (as observed by a plateauing of the fluorescence signal). Addition of the protonophore CCCP to a final concentration of $\sim 100 \mu \mathrm{M}(1.6 \mu \mathrm{l}$ of a $100 \mathrm{mM}$ stock made up in ethanol) in the assay mixture should be performed to abolish $\Delta \mathrm{pH}$-driven, MdtM-mediated antiport activity. Addition of CCCP will cause a further dequench of the fluorescence signal as the $\Delta \mathrm{pH}$ is dissipated (see Figure 1). Record the fluorescence signal for a further $\sim 50 \mathrm{sec}$ then terminate the acquisition and save the electronic data.

6. Decant the cuvette contents into a suitable waste container and wash the cuvette thoroughly with ethanol then high-purity water. Dry the cuvette carefully with compressed air. 


\section{Representative data}

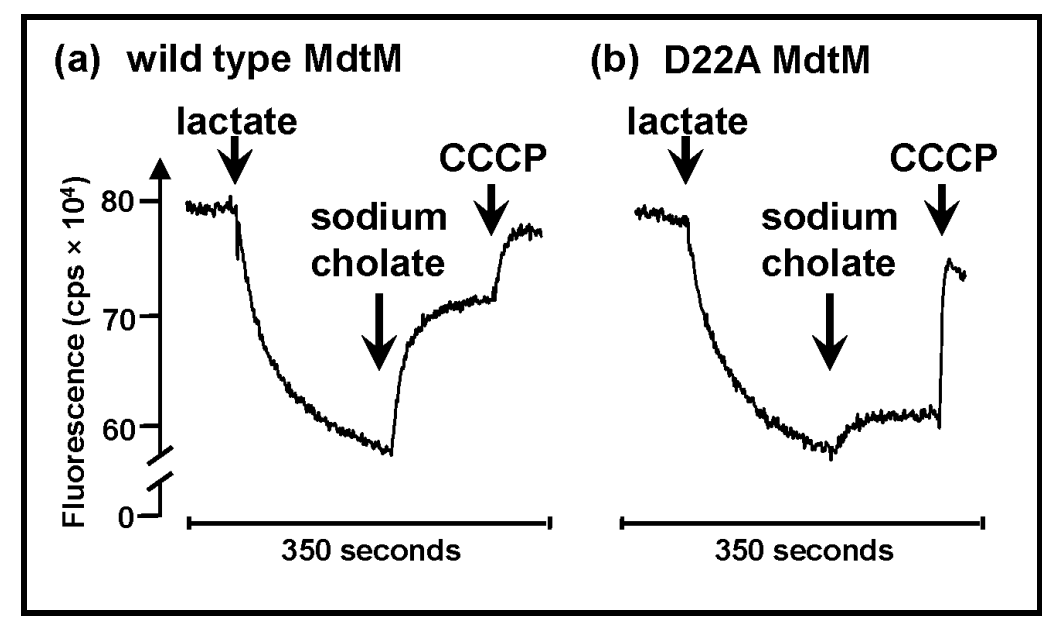

Figure 1. Representative measurements of the fluorescence quench/dequench of acridine orange upon addition of bile salts to inverted vesicles of E. coli TO114 cells that overproduced recombinant (a) wild type MdtM or, as a control, (b) the dysfunctional MdtM D22A mutant. Respiration-dependent generation of $\Delta \mathrm{pH}$ (acid inside) was established by addition of sodium DL-lactate as indicated. Sodium cholate was added to vesicles as indicated to initiate the transport reaction and CCCP was used to dissipate $\Delta \mathrm{pH}$. The fluorescence dequench observed in the control experiment (panel b) upon addition of sodium cholate is due to antiport activity of chromosomally encoded MdtM. Fluorescence intensity is measured in counts per second (cps). Note that the fluorescence intensity you measure may differ depending upon how your instrument is set up. The traces above are representative of experiments performed in triplicate on at least two separate preparations of inverted vesicles.

\section{$\underline{\text { Notes }}$}

1. To ensure reproducibility, the assays should be performed in triplicate on at least two separate preparations of inverted vesicles.

2. If the fluorescence signal does not quench, or enhances, the vesicles have either not maintained integrity or are not inverted and their preparation needs to be repeated.

3. As with all assays that rely on detection of fluorescence, robust controls must be in place to ensure that any detected transport activity can be attributed unambiguously to the protein of interest. In our experiments, we used inverted vesicles that overexpressed MdtM D22A, a dysfunctional point mutant of MdtM, as a negative control (see Figure 1b). 
4. If the method is to be used for detection of metal ion $/ \mathrm{H}^{+}$antiport activity, the use of inverted vesicles generated from the antiporter-deficient TO114 strain of $E$. coli is important because at least four other transporters (NhaA, NhaB, ChaA and MdfA) present in the bacterium catalyse a monovalent metal cation $/ \mathrm{H}^{+}$exchange.

5. Finally, if this protocol is used for comparison of antiport activities of wild type and mutant transporters, the amount of target protein present in the inverted vesicle membranes must be quantified (usually by immunodetection methods) to ensure that any measured differences in $\mathrm{H}^{+}$uptake are due solely to differences in the activity of the transporters and not to differences in expression levels.

\section{$\underline{\text { Recipes }}$}

1. LBK agar (100 ml)

\section{$1.0 \mathrm{~g}$ tryptone}

$0.5 \mathrm{~g}$ yeast extract

$0.745 \mathrm{~g} \mathrm{KCl}$

\section{$1.5 \mathrm{~g}$ agar}

Make up to $100 \mathrm{ml}$ with high purity water then autoclave

Add $100 \mu \mathrm{g} / \mathrm{ml}$ carbenicillin for selection when the solution is still liquid and warm to the touch

Add to Petri dishes under sterile conditions

2. LBK liquid medium ( $1 \mathrm{~L})$

$10 \mathrm{~g}$ tryptone

$5 \mathrm{~g}$ yeast extract

$7.45 \mathrm{~g} \mathrm{KCl}$

Make up to $1,000 \mathrm{ml}$ with high purity water then autoclave

3. Tris/choline/dithiothreitol/sucrose (TCDS) buffer (1 L)

Consisting of $10 \mathrm{mM}$ Tris- $\mathrm{HCl}(\mathrm{pH} 7.5), 140 \mathrm{mM}$ choline chloride, $0.5 \mathrm{mM}$ dithiothreitol and $250 \mathrm{mM}$ sucrose

$1 \mathrm{M}$ Tris- $\mathrm{HCl}(\mathrm{pH} 7.5) 10 \mathrm{ml}$

$2 \mathrm{M}$ choline chloride $70 \mathrm{ml}$

$1 \mathrm{M}$ sucrose $250 \mathrm{ml}$

Make up to $999.5 \mathrm{ml}$ with high purity water then check $\mathrm{pH}$ and adjust if necessary with $\mathrm{HCl}$

Autoclave or sterile filter and store at $4{ }^{\circ} \mathrm{C}$

Add $0.5 \mathrm{ml}$ dithiothreitol from frozen $1 \mathrm{M}$ stocks immediately before use

4. Transport assay buffer $(100 \mathrm{ml})$ 
Consisting of $10 \mathrm{mM}$ BisTris propane (pH 7.2), $5 \mathrm{mM} \mathrm{MgSO}_{4}, 1 \mu \mathrm{M}$ acridine orange

$100 \mathrm{mM}$ BisTris propane $(\mathrm{pH} 7.2) 10 \mathrm{ml}$

$2 \mathrm{M} \mathrm{MgSO}_{4} 0.25 \mathrm{ml}$

$10 \mathrm{mM}$ acridine orange $10 \mu \mathrm{l}$

Make up to $100 \mathrm{ml}$ with high purity water then sterile filter

Acridine orange is light sensitive so both the transport assay buffer and acridine orange stocks should be stored either in amber bottles or in a container protected from light at 4

${ }^{\circ} \mathrm{C}$ in the dark

5. $200 \mathrm{mM}$ sodium DL-lactate solution (10 ml)

$0.45 \mathrm{ml} 50 \%$ sodium DL-lactate aqueous solution

Make up to $10 \mathrm{ml}$ with high-purity water

Sterile filter and stored at $4{ }^{\circ} \mathrm{C}$

\section{Acknowledgements}

This work was supported by BBSRC grant BB/K014226/1 (to CJL). The protocol described above is adapted from one reported previously (Resch et al., 2010).

\section{$\underline{\text { References }}$}

1. Paul, S., Alegre, K. O., Holdsworth, S. R., Rice, M., Brown, J. A., McVeigh, P., Kelly, S. M. and Law, C. J. (2014). A single-component multidrug transporter of the major facilitator superfamily is part of a network that protects Escherichia coli from bile salt stress. Mol Microbiol 92(4): 872-884.

2. Reddy, V. S., Shlykov, M. A., Castillo, R., Sun, E. I. and Saier, M. H., Jr. (2012). The major facilitator superfamily (MFS) revisited. FEBS J 279(11): 2022-2035.

3. Resch, C. T., Winogrodzki, J. L., Patterson, C. T., Lind, E. J., Quinn, M. J., Dibrov, P. and Hase, C. C. (2010). The putative $\mathrm{Na}^{+} / \mathrm{H}^{+}$antiporter of Vibrio cholerae, Vc-NhaP2, mediates the specific $\mathrm{K}^{+} / \mathrm{H}^{+}$exchange in vivo. Biochemistry 49(11): 2520-2528. 